\title{
The Impact of Makerspaces on Engineering Education
}

\author{
Mohamed Galaleldin, Francois Bouchard, Dr. Hanan Anis, Claude Lague, \\ University of Ottawa \\ mgala028@uottawa.ca,hanis@uottawa.ca
}

\begin{abstract}
Makerspaces are gaining more ground in universities and other educational institutions as a novel approach to boost creativity, innovation, and provide more opportunities for experiential and hands-on learning experience. Albeit being multidisciplinary, and open spaces in nature, Makerspaces still lack integration to the curricula of engineering schools. With increasingly competitive markets, there is a need to educate future engineers with necessary skills to be more creative and to be able to compete in today's global market. A twophase study was developed to study the integration of the Makerspace concept in engineering schools. The first phase was based on interviews with five North American University Makerspaces that vary in size, objective, business model, and management structure to identify best Makerspace practices in preparation of the establishment of the University of Ottawa's Richard L'Abbé Makerspace. The second phase was a survey administered to engineering students who have used the Richard L'Abbé Makerspace since its opening in the fall of 2014 to assess its impact on their engineering competencies, in particular design skills, problem analysis, communication and team work skills, investigation skills, and entrepreneurial skills. This paper aims at studying best practices of Makerspaces on campus and their impacts on engineering education and on the development of desired skills and competencies for engineering students.
\end{abstract}

Keywords: Makerspace, Engineering Education, Engineering Competencies, Maker Movement.

\section{INTRODUCTION}

Engineers today need to be ready to enter the work force and thrive in an ever-changing global economy. They need to be flexible, resilient, creative, empathetic, and have the ability to recognize and seize opportunities. In addition, they need to be able to communicate effectively with their peers, and as leaders in their teams (Byers, T. et. Al; 2013).
Makerspaces offer an opportunity to educate future engineers to harness creativity in order to stay competitive and relevant in an economy with growing needs and develop a large range of skills currently underdeveloped (Wilczynski, V.; 2015).

Makerspaces provide students with access to handson, state of the art prototyping technologies, encourage collaboration between diverse teams of students from all years and majors, bolster design within engineering curricula, and extracurricular activities and enable students to tackle open-ended, real world challenges (Forest, C. et al., 2014). Furthermore, Makerspaces empower students to fabricate their own design, which helps them to achieve a deeper learning experience, and gain higher satisfaction (Baleshta, J.; 2015). Makerspaces also contribute to producing more student entrepreneurs (Holm, E. J. Van; 2015). Makerspaces also work to strengthen community ties by offering a space for the community that facilitate and foster broader community life (Moilanen, J.; 2012).

With the increased attention to the role of design throughout the engineering curriculum, the increased awareness of the value of active learning and teambased problem solving, the increased support for both faculty-led and student-led entrepreneurship activities, all coupled with the culture shift on college campuses influenced by the maker movement have played major role in inspiring universities to invest in Makerspaces. (Wilczynski, V.; 2015).

This study was done in two phases. The first was survey of five university Makerspaces in North America to decide on the best business model and management structure for the University of Ottawa Makerspace. The goal of opening a Makerspace on campus was to improve the students experience by fostering multidisciplinary collaboration across campus, provide student entrepreneurs with access to high-end prototyping equipment, increase the University of Ottawa community engagement. 
The second phase was performed two years after the opening of the University of Ottawa Makerspace was to assess its impact on engineering students' competencies.

\section{METHODOLOGY}

\section{Phase 1}

In phase 1, we conducted interviews via Skype with five university Makerspace managers in North America. Interviews were transcribed verbatim and analysed in order to gain insight into their operational strategy and management structure. Data was organized from the interviews and coded to identify patterns and themes.

The sampling method used for this study was purposive sampling, Makerspaces selected for this study were different and unique in their size, objective and organizational structure. The selection criteria of the Makerspaces were based on extensive Internet research as well as the availability and response of the approached universities.

We have studied the management structure, the revenue/cost models, the targeted customers/audience of the Makerspaces, the marketing techniques, their value proposition, the relationship between the campus Makerspaces and the off campus maker community, and the strategic goals of these Makerspaces. The five Universities interviewed were: John Hopkins University, University of Michigan, Georgia Institute of Technology, Queen's University, and the University of Victoria.

\section{Phase 2}

A survey was administered in April 2016 to all Makers who attended an event at the uOttawa Richard L'Abbé Makerspace between September 2014 and April 2016. Due to time limitations our sample size for this phase was 49 makers, of which 30 were uOttawa students and 19 were of the public. Engineering students were asked to self-assess the Makerspace impact on their skills; in particular, problem solving, communication and team work, investigation, design, and entrepreneurial skills. Nonengineers were asked to comment on their experience in the Makerspace and were asked if they would agree to participate in future research.

\section{Discussion and Analysis}

Phase 1 was focused on exploring Makerspaces in University campuses, and studying the business models and management structure of the Makerspaces. The collected quantitative data are summarized in the following sections:

\subsection{Objectives of the Makerspaces}

Objectives of Makerspace vary greatly depending on the vision/mission of the Makerspace, the support the it gets from the University, and the level of success that these Makerspaces have had until now.

All Makerspaces were consistent in their effort to provide resources to their targeted students with means to access equipment, tools and materials as necessary and to enrich students' life on campus.

Makerspaces that were design oriented - such as the Invention Studio at Georgia Tech, and the FabLab at the Taubman School of Architecture and Urban Planning - aimed to be the center of design on campus and to foster innovation by offering a multidisciplinary space where students from different faculties can meet and work on projects together.

On the other hand, Makerspaces that emphasized research - such as MakerLab at the University of Victoria - aimed at supporting research projects and provide students with research grants.

\subsection{Elements of Makerspace Business Model}

\subsubsection{Value Proposition}

Makerspaces provide areas that are equipped with state of the art tools and equipment that are difficult for students or individuals to access. In addition, they offer training and workshops, provide support to users with their projects by either helping them with accomplish/make the project, or by connecting makers together to collaborate on projects together.

The value proposition of the Makerspaces is presented in the following table

\begin{tabular}{|l|l|l|l|l|}
\hline University & Classes & $\begin{array}{l}\text { Access to } \\
\text { Tools \& } \\
\text { Equipment }\end{array}$ & $\begin{array}{l}\text { Project } \\
\text { Grants }\end{array}$ & $\begin{array}{l}\text { Resear } \\
\text { ch } \\
\text { Grants }\end{array}$ \\
\hline $\begin{array}{l}\text { University } \\
\text { of Michigan }\end{array}$ & No & Yes & No & Yes \\
\hline $\begin{array}{l}\text { John } \\
\text { Hopkins } \\
\text { University }\end{array}$ & Yes & Yes & Yes & No \\
\hline Queen's & Yes & Yes & No & No \\
\hline
\end{tabular}




\begin{tabular}{|l|l|l|l|l|}
\hline University & & & Yes & No \\
\hline $\begin{array}{l}\text { Georgia } \\
\text { Institute of } \\
\text { Technology }\end{array}$ & Yes & Yes & Yes & \\
\hline $\begin{array}{l}\text { University } \\
\text { of Victoria }\end{array}$ & Yes & Yes & No & Yes \\
\hline
\end{tabular}

\subsubsection{Target Audience}

Every Makerspace has a unique target audience depending on its intended goals, and available resources.

The Invention studio at Georgia Institute of technology is targeting all students on campus. On the contrary, The MakeLab at the University of Victoria is aimed at researchers in Media History from the Faculty of Arts, while the FabLab at the Taubman College of Architecture is only targeting students from the Faculty of Architecture and not open to students from different faculties at the University of Michigan; the others are open to every student on campus.

\subsubsection{Financial Model}

The financial Model adopted by a Makerspace often shapes its approach to the accessibility of the public to the Makerspace, the budget, the integration of curriculums in the Makerspace.

All surveyed Makerspaces are funded through university grants and financed through different departments and faculties except for the SparQ Lab at Queen's University that is based on a subscription model, due to the independence of the Makerspace from the university (student-run). The Invention Studio at Georgia Tech, is funded through the university, while constantly moving towards an industry sponsorship model.

\subsubsection{Key Partners}

Partners of the makerspaces were in correlation with their business model. Research-oriented makerspaces, such as the MakeLab at the University of Victoria, partners with professors and research centres in universities. Others are more independent; for example: The Queen's University SparQ Lab is more independent therefore their partners are students who provide the classes and sponsors who fund the space.

Makerspaces such as the Digital Media Centre at John Hopkins University, and the FabLab at the
Taubman School of Architecture also work to form partnerships with makerspaces outside university campus, and research/innovation centres.

\subsubsection{Accessibility and hours of operation}

One of the main characteristics of makerspaces is its accessibility to the public and to different segments of people. We have found that some of the Makerspaces are accessible to the public while others are not.

Funding can limit accessibility of the Makerspace to certain segments of the student population on campus or the public.

In addition, available resources, safety strategy, and the available space area of the makerspace all can limit the accessibility of a University makerspace.

Only two of the makerspaces surveyed provided access to all students on campus, the Invention Studio, and the SparQ Lab.

All of the makerspaces that we have analysed were open during the morning and later in the afternoon. The Invention Studio was adopting a strategy targeting students at their availability times, the space is open during the morning and the afternoon to all students and is open during all hours of the day to student volunteers as a reward for their service.

\subsubsection{Staffing and Management Structure}

Staffing varies significantly from spaces that are run by a single professor (Victoria) to those that are run by students only (Queen's). Many Makerspaces are operated on a full-time basis by hired staff. The invention studio has a management structure that is composed of a board of directors that is made of students and faculty members. The activities and operations of the space are the responsibility of student volunteers. Students are not paid for their works but they receive more access time than a normal student would be allowed and only volunteers are eligible to apply for project grants.

\subsubsection{Integration with Curriculum}

The Invention Studio stands out as it had a high level of integration of the space in the curriculum. In addition, the link between the space and the design projects connected the various departments in the 
Faculty of Engineering and the space. The rest of the Makerspaces did not attempt to integrate the Makerspace with the curriculum.

\subsection{The uOttawa Richard L’Abbé Makerspace}

uOttawa opened the Richard L'Abbé Makerspace at the Faculty of Engineering targeting to create a space that can foster innovation, promote multidisciplinary projects, provide access to niche equipment and tools, provide a space for students to realize their engineering design projects, and provide a space that can be a hub for student entrepreneurs.

The Richard L'Abbé Makerspace integrates some of the features of the Invention Studio and the Digital Media Centre at John Hopkins University as well as opted for a number of unique features based on its specifics.

The Makerspace adopted a model that granted free accessibility to all students on campus during the week and to the public on Sundays. The Makerspace is open between 12:00 and 20:00 during the week and 11:00 to 17:00 on Sundays. The Makerspace also adopted a staffing model that relied on students who are paid to manage the day-to-day activities of the Makerspace, and faculty to provide oversight and strategic direction.

The Makerspace started with a humble beginning. It had limited equipment and most of it were available through the Faculty of Engineering outreach program and included some 3D printers and Arduinos. Operational funding in the initial year was provided by the Faculty of Engineering as well as the Ontario Centre of Excellence (for the public access portion). The Richard L'Abbé Makerspace significantly expanded in its second year in size, complexity of equipment and sources of funding. Two years since its inauguration, the Richard L'Abbé Makerspace held 130 workshops and events, has been used by more than 2,000 Makers - uOttawa students and members of Ottawa's public and is well funded through both public and private money.

\subsection{Phase 2: Makerspace Impact on Engineering Education}

Respondents were asked to rate their experience at the Richard L'Abbé Makerspace and its impact on their engineering competencies through open-ended questions, and a 1 to 5 Likert-Type scale, 1 being strongly disagree and 5 strongly agree. Engineering competencies were communication and teamwork skills, problem solving skills, design skills, investigation skills, and entrepreneurial skills. Survey questions and criteria used to assess the Makerspace's impact on student's skills were derived from the CEAB graduate attributes accreditation criteria.

To-date, we were able to analyze 49 responses to our survey, 35 were males, and 14 were females. 30 of the respondents were uOttawa students and 19 were members of the public. Out of the 30 only 2 were from other faculties than the Faculty of Engineering. $20 \%$ of the respondents said they frequent the makerspace on a weekly basis, $30 \%$ once a month and $35 \%$ said they have participated actively one semester while a $15 \%$ seldom use the Makerspace.

$75 \%$ of the respondents used the Makerspace for extracurricular projects, and a similar percentage participated in a workshop at the Makerspace. Workshop topics attended by respondents were: 3D Printing, laser cutting, Arduino classes, Internet of things, and Android Development.

$60 \%$ of the respondents participated in a group project, and only 1 respondent worked in a multidisciplinary team.

\subsection{Communication and Team Work skills}

Only the $60 \%$ of the respondents that worked in a group environment in the Makerspace were asked to evaluate how their experience at the Richard L'Abbé Makerspace influenced their communication and teamwork skills. $80 \%$ of the respondents said the Makerspace enabled them to be more confident to translate engineering concepts to non-engineers, while only $45 \%$ said that they had conversations with end-users of their design which helped them iterate their design. Respondents cited having conversations with other engineers and makers about their designs, and acquiring knowledge about niche topics in the makerspaces as main reasons in of how the Richard L'Abbé Makerspace has helped them to be more confident in their communication and team work skills.

\subsection{Problem Solving Skills}

Out of the engineering students who took the survey, $62.5 \%$ said the makerspace enabled them to work on 
a problem-based project, and only $40 \%$ said that they have identified that problem in the Makerspace. $60 \%$ of the respondents said that they feel more confident in their engineering knowledge and skills to solve a complex engineering problem after working in the Richard L'Abbé makerspace citing "going from theory to practice", prototyping CAD designs, continuous iteration of designs, and an environment that enables students to gain hands-on experience in Engineering.

\subsection{Investigation Skills}

Only $30 \%$ of the respondents said the makerspace helped them in improving their investigation skills, $46 \%$ were neutral and $24 \%$ said the makerspace had no impact on their investigation skills. When asked if peer feedback in Makerspace has helped them to improve their design only $20 \%$ agreed, and $40 \%$ said that peer feedback had no impact on their design. Students who sensed that the makerspace impacted their investigation skills referred the impact to the creative environment offer in the space and the ability to investigate different solutions for their engineering problems.

\subsection{Design Skills}

When asked of the Makerspace impact on the respondents' confidence level in their design skills 90\% answered positively, and mentioned designing for manufacturability, ability to prototype, easy accessibility to equipment and materials, ability to test solutions, improving design skills through experience all were factors of how the makerspace helped them to become more confident in their designing skills.

$60 \%$ of the respondents said they were able to propose more than one solution for their engineering solutions, and $75 \%$ said the makerspace helped them to finalize their design projects by demonstrating limitations/restrictions of manufacturing methods, offering accessibility to equipment and tools, and guidance on how to realize the design project.

\subsection{Entrepreneurial and Management Skills}

$54 \%$ of the respondents said that the Makerspace enabled them to work on their entrepreneurial ideas and investigate new ideas. $38.5 \%$ said their schedule management skills has improved due to working the makerspace, and $62 \%$ said their resource management skills has improved through working in the makerspace.

$58 \%$ of the respondents said the Richard L'Abbé Makerspace offered them an entrepreneurial environment on campus, while $17 \%$ disagreed and $25 \%$ remained neutral.

Only $15 \%$ of the respondents said that they have recruited team members to their design teams, and only $23 \%$ said they were introduced to funding opportunities through the makerspace.

\subsection{Conclusion}

The Richard L'Abbé Makerspaces aims to foster innovation, provide access to resources, and multidisciplinary projects. Moreover, the space is open to students from across campus and members of the public.

The Richard L'Abbé Makerspace helped its members to become more confident in their communication and teamwork skills. In addition, it enabled students to investigate and solve an engineering problem, and to gain more confidence in their engineering knowledge through hands-on experience, prototyping, and continuous iterations of their designs. Furthermore, the Makerspace helped students to be more confident in their design skills, and helped them to finalize their design projects by demonstrating limitations/restrictions of manufacturing methods, prototyping, and providing guidance.

More needs to be done to further integrate the Makerspace in the engineering curriculum. In addition, the Makerspace should offer more multidisciplinary opportunities to connect makers across campus and offer workshops and opportunities where students can improve their entrepreneurial skills.

\subsection{Limitations}

While Phase 1 was limited by the sampling methodology we used and the structure of the surveyed makerspaces, it provided us guidance on the business model, management structure best practices required to launch the Makerspace at the University of Ottawa.

Relying on student self-assessment of their engineering competencies, limits our phase 2 study by raising the concerns of credibility, self- 
enhancement, consistency seeking, and selfpresentation (Robins and John, 1997). Bidirectional response options were used to ensure the internal consistency of the survey (Barnette J, J; 2000). In addition, due to time constraints our sample size was small relative to the total number of users of the space. However, phase 2 is in its early stages. We expect to collect a larger sample size in the months to come. We also intend to explore a number of related topics including how to better integrate the Makerspace in our engineering curricula.

\subsection{Acknowledgement}

The authors would like to thank Natural Science and Engineering Research Council (Chair in Entrepreneurial Engineering Design), Richard L'Abbé (Entrepreneurship and Endowment fund and the Centre for Entrepreneurship and Engineering Design) and Ontario Centre of Excellence (Campus Led A).

\subsection{References}

[1] C. R. Forest, R. A. Moore, A. S. Jariwala, B. B. Fasse, J. Linsey, W. Newstetter, P. Ngo, and C. Quintero, "The invention studio: A university maker space and culture," $A d v$. Eng. Educ., vol. 4, no. 2, 2014.

[2] E. J. Van Holm, "Makerspaces and Contributions to Entrepreneurship," Procedia - Soc. Behav. Sci., vol. 195, pp. 24-31, 2015.

[3] J. Moilanen, "Emerging Hackerspaces Peer-production Generation," pp. 94-111, 2012.

[4] A. Rogers, B. Leduc-Mills, B. C. O'Connell, and B. Huang, "Lending a hand: Supporting the maker movement in academic libraries," in ASEE Annual Conference and Exposition, Conference Proceedings, 2015, vol. 122nd ASEE, no. 122nd ASEE Annual Conference and Exposition: Making Value for Society.

[5] A. Tom Byers, Tina Seelig, Sheri Sheppard and P. Weilerstein, "Entrepreneurship: Its Role in Engineering Education," Bridg. Natl. Acad. Eng., vol. 43, no. 2, 2013.

[6] V. Wilczynski, "Academic maker spaces and engineering design," in ASEE Annual Conference and Exposition, Conference Proceedings, 2015, vol. 122nd ASEE, no. 122nd ASEE Annual Conference and Exposition: Making Value for Society.
[7] T. William Barrett, R. L. Nagel, and K. P. Grau Talley, "A Review of University Maker Spaces."

[8] Robins, R. W., \&John, 0. P. (1997). The quest for self- insight: Theory and research on accuracy and bias in self-perception. In R. Hogan, J. A. Johnson, \& S. R. Briggs (Eds.), Handbook of personality psychology (pp. 649-679). San Diego, CA: Academic Press.

[9] BARNETTE, J. J. (2000). Effects of STEM and Likert response option reversals on survey internal consistency: if you feel the need, there is a better alternative to using those negatively worded stems. EDUCATIONAL AND PSYCHOLOGICAL MEASUREMENT. 